\title{
MIASTENIA GRAVE
}

\author{
TRATAMENTO COM TIMECTOMIA, CORTICóIDE E PLASMAFERESE
}

\author{
ELZA DIAS-TOSTA * - RUBENS NELSON MORATO-FERNANDES **
}

\begin{abstract}
RESUMO - Após introdução sobre a etiopatogenia da miastenia grave e divergências quanto às várias modalidades terapêuticas, os autores mostram os resultados favoráveis obtidos com a timectomia isoladamente (13 casos): $15,3 \%$ com remissāo completa (2 de 13), 46,15\% com melhora importante (6 casos), $30,7 \%$ com melhora de apenas um grau na escala de atividade (4 casos). A associaçåo de corticosteróide e/ou plasmaferese elevou para 14,8\% a remissâo (4 do total de 27 casos); $74 \%$ apresentaram melhora (20 casos), 7,4\%, piora (dois casos) e um caso năo apresentou resposta às diferentes terapêticas. Na sua casuisticu mostram ainda que a corticoterapia deve entrar como terapêtica de segunda linha, devido a seus efeitos colaterais e à difjculdade na restirada; apontam a plasmaferese como tratamento da emergência miastênica. Fazem ainda revisão da literatura quanto ao uso de outros imunossupressores nâo esteróides.
\end{abstract}

\section{Myasthenia gravis: thymectomy, corticosteroid and plusmapheresis therapy.}

SUMMARY - This paper reviews a 12 year experience with myasthenia gravis management (surgical and drug therapy). A total of 27 patients were submitted to thymectomy, and 12 out of 13 showed fairly good results with this only form of therapy (15.3\% with complete remission, $46.15 \%$ with marked improvement and $30.7 \%$ with moderate improvement). The other 14 need either a combination of surgery and plasmapheresis or corticosteroids with the cummulative results of: $14.8 \%$ of remission (4 out of 27 ), $74 \%$ of improvement (20 out of 27), 7.4\% of worsening (2 out of 27) and $3.7 \%$ without change (1 out of 27). Two other patients not submitted to surgery showed either a stable state of their symptoms or a mildy worsening. Another eight patients not submitted to surgery could not be bollowed up. The authors also conclude by the validity of the use of plasmapheresis in myasthenic crises leading to a transient relief of the symptoms and suggest the use of corticosteroids as a second choice, due to their undesirable side effects and difficulty in their reduction and elimination without worsening the symptoms. Other immunosuppressive drugs could be used in cases in which those above cited therapies showed unsuitable results.

A miastenia grave (MG) é patologia pouco freqüente ocorrendo numa incidência de $0,4 / 100000^{13,22}$, cujo quadro clínico já está bem definido, sendo suas características principais a oftalmoplegia, acometimento de musculatura proximal e bulbar, com flutuações e fatigabilidade importantes. O conhecimento de sua fisiopatologia, mostrando que está relacionada à presença de anticorpos anti-receptor de acetilcolina na porção pós-sináptica da placa mioneural, é devido aos trabalhos pioneiros de Engel 8. Entretanto, ainda não se conseguiu estabelecer correlação estreita entre niveis de anticorpos circulantes e gravidade da doença. Quanto ao papel do timo na etiopatogenia da doença, Lisak e Barchi 14 citam a presença de antigeno no timo comum ao músculo, a presença de receptores de acetilcolina, a presença de células no timo capazes de

Unidade de Neurologia do Hospital de Base do Distrito Federal (HBDF): * Médica Neurologista, atualmente no Hospital de Doenças do Aparelho Locomotor (HDAL)/SARAH; ** Médico Neurologista. 
produção de anticorpos contra receptores de acetilcolina que, portanto, sugerem patologia intra-tímica. Haynes e col.11 mostram que nos casos de timo atrófico ocorrem mudanças no número de linfócitos $T$ e sugerem que o timo atrófico produziria fator responsável por essas mudanças ligadas ao nivel de cortisol plasmático. É por isto que o estudo da MG continua fascinante, havendo ainda outros fatos de dificil explicação como a presença de timoma com sintomas miastênicos precedendo a descoberta do tumor, timoma sem miastenia e finalmente o aparecimento de miastenia grave anos após a retirada do tumor mediastinal, histologicamente provado tratar-se de timoma 17,19. Com tal variedade de comportamento, é natural que surjam controvérsias quanto à melhor forma de tratamento dessa patologia. Alguns autores 3,17,26,27 são enfáticos em indicar a timectomia precoce, enquanto outros 1 relatam resultados semelhantes nas duas condutas (cirúrgica e conservadora), quando afirmam que thouve influência da terapêutica na resposta clínica a curto e longo prazos nos pacientes timectomizados e a longo prazo nos pacientes submetidos a tratamento conservador'. Outros ainda levantam dúvidas sobre a efetividade da terapêutica cirúrgica, considerando que as melhoras observadas seriam dependentes de flutuaçōes espontâneas 16,36. A este ponto de vista contrapõem-se Scadding e col.26, que mostram a baixa taxa de remissão espontânea e a sua curta duração em casos não tratados.

Acreditamos, pois, oportuno relatar a experiência adquirida nestes 12 anos no tratamento de pacientes com MG no $\mathrm{HBDF}$ e na clínica particular de um dos autores, analisando os resultados obtidos com tratamento cirúrgico, anticolinesterásicos, corticosteróides e plasmaferese, sendo desejável a publicaçăo de maior número de resultados de grupos estudiosos de $M G$, somando-se experiências para a solução de tão grave problema.

\section{CASUfSTICA E MÉTODOS}

De um total de 38 casos de MG diagnosticados no período de 1976 a junho de 1987, 29 casos foram incluídos na avaliaçāo terapêutica, sendo 27 submetidos a timectomia trans-esternal e dois, a tratamento clínico não cirúrgico. Os 9 casos restantes não foram incluídos na avaliaçāo da resposta terapêtica por faita de seguimento. Os 29 casos foram divididos em 5 grupos baseados na classificação de Osserman modificada (I-forma ocular; IIA-generalizada leve; II-B-generalizada moderada; III-aguda fulminante; IV-severa tardia (após dois anos): V-predominantemente ou apenas bulbar). O estado físico do paciente foi graduado conforme a capacidade de realizar determinada atividade ou com relaça ao comprometimento respiratório. Esta escala de atividade foi adaptada de Tejedor e Orozco (33) (Tabela 1) e os critérios de resposta ao tratamento instituído foram padronizados conforme a avaliaçāo da escala de atividade adaptado dos mesmos autores (A-remissão completa sem medicaçāo; B-assintomático com medicação; C-melhora com medicação; D-estacionário; E-piora). Consideramos remissăo quando não havia mais sinais da doençā, melhora quando subia um ponto ou mais na escala de atividade, estacionário quando nāo mudava na escala de atividade e piora quando descia um ponto ou mais na citada escala. Trata-se, portanto, de 29 casos de MG, adquirida, sendo apenas duas timomatosas (II-9, IIB-15). A confirmação diagnóstica de todos se fez pelo exame ciĺnico e laboratorial, seja eletrofisiológico (estimulaçăo repetitiva) ou farmacológico (teste do cloridrato de edrofônio cu da prostigmina), alêm de estudos radiológicos (RX simples, pneumomediastino, tomografia simples e/ou computadorizada de mediastino). O estudo anátomo-patológico da glândula só não foi realizado em um caso.

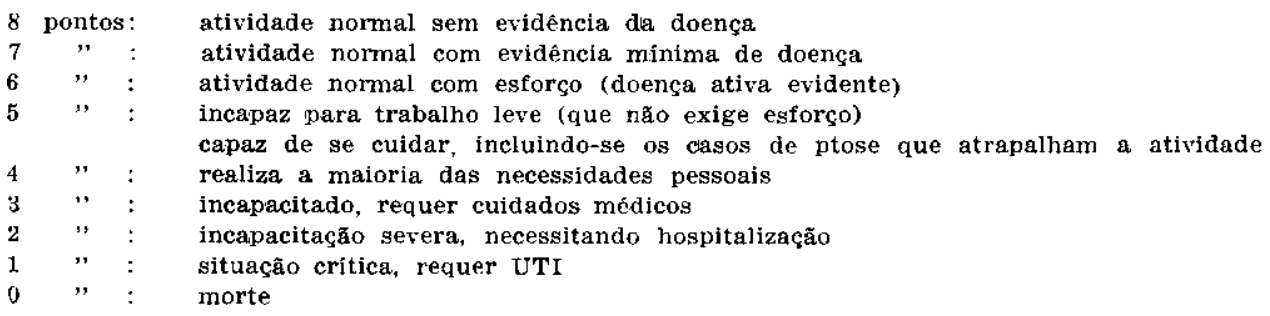


Foram realizados exames :aboratoriais também para a verificaçāo da presença de doenças associadas, como as tireoideanas, do colágeno e outras; os achados sāco apresentados na tabela 2.

O tempo de segumenty variou de dois meses a 12 anos. Para cada modalidade terapêutica estudou-se a resposta considerando-se três fases pós-timectomia: a curto prazo - até um ano de acompanhamento; a médio prazo $\rightarrow$ de um a dois anos re acompanhamento: a longo prazo - acima de dois anos de acompanhamento. Foi analisada ainda a resposta obtida ao tratamento clínico pré-cirúrgico e foi realizado estudo comparativo dos nossos resultados com os que estão citados na literatura. A introdução de prednisona foi progressiva até uma dose máxima que variou de $70-100 \mathrm{mg}$ diariamente, e em 4 casos (IIB-4, IIB-8, IIB-9, V-3) empregou-se até a dose de $120-150 \mathrm{mg}$ em dias alternados. A duraçāo do tratamento com o corticóide variou de dois meses a três anos desde sua introdução até sua retirada (naqueles casos em que se conseguiu suspender). A plasmaferese variou de 7-10 sessões, sendo trocado um volume de $1000 \mathrm{ml}$ em cada sessão.

I

Púrpura Trombocitopênica- (caso 2)

Alterações das Globulinas- (caso 3)

Alterações das Imunoglobulinas- (caso 1)

IIA

Asma e enxaqueca- (caso 9)

Diabetes Mellitus + Hipertensão Arterial + Hipertireoidismo- (caso 4) Galactorréia e Alergia- (caso 5)

Alterações das Globulinas- (casos 3, 4.6)

Alteraçōes das Imunoglobulinas- (casos 4, 6, 10)

IIB

Infecçòes de Vias Aéreas. (casos 1, 6, 12)

Sindrome de Stein Loeventhal. (caso 8)

Sindrome Reumática e Neuralgia do Trigêmeo- (caso 5)

Amenorréia e Galactorréia- (caso 12)

Convulsões e Hemorragia Subaracnoide Espontânea- (caso 13)

Alteraçōes das Globulinas- (casos 4, 5, 7, 14)

Alteraçôes das Imunoglobulinas- (casos 5, 13, 14)

V

Tireoldite de Hashimoto- (caso 1)

Bocio Uninodular frio- (caso 5)

Infecções Respiratorias- (caso 2)

Encefalite- (caso 4)

Artralgias e Costela Cervical- (caso 6)

Hipertensão Arterial Sistêmica. (caso 7)

Alteraçōes das Globulinas- (casos 5, 6)

Alterações das Imunoglobulinas. (casos 4, 6, 7)

Trebela 2 - Miastenia grave $\varepsilon$ doenças associadas.

\section{RESULTADOS}

A faixa etária em que se observa maior concentração de pacientes coincide à citada na literatura: média de idade de 26 anos para o sexo feminino (29,30), ou seja, houve predominio na faixa etária de 21-30 anos para o sexo feminino; para o sexo masculino, observamos predomínio na faixa de 61-70 anos (Fig. 1). Nossos resultados quanto às diferentes modalidades terapêuticas estão relacionados globalmente nas tabelas 3 e 4: 27 pacientes submetidos a timectomia e 10 que receberam apenas tratamento clinico.

Dos pacientes timectomizados tivemos 13 que só receberam este tipo de tratamento (Tabela 5) que foram divididos, segundo o acompanhamento, em: longo prazo (IIA-6, IIB-2, IIB-5, IIB-12, IIB-15, V-1, V-4), médin (IIB-10) e curto prazo (IIA-4, IIA-5, IIA-10, 


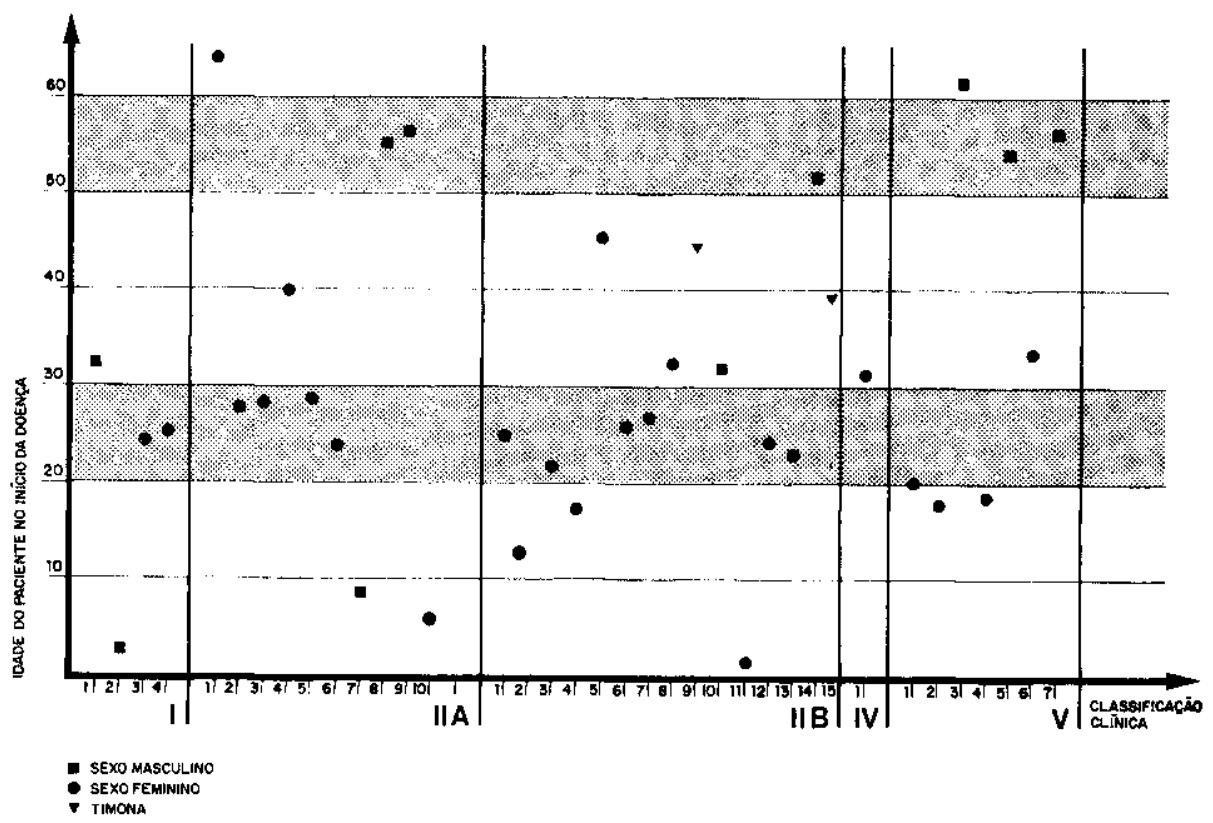

Fig. 1 - Miastenia grave: distribuicão da droga nos diferentes grupos de acordo com a faixa etaria.

IIB-13, 1IB-14). Os resultados a longo trazo dos 7 pacientes citados foram de remissão completa em um caso (IIB-15) e de melhora em 6, evoluindo na escala de atividade de vida normal com esforço, para vida normal com sinais minimos de doenca (IIA-6) ou evoluiram até dois pontos ou mais na escala de atividade (5 casos restantes), ficando 4 em escala de atividade $7 \mathrm{e} \mathrm{um,} \mathrm{em} \mathrm{escala} \mathrm{de} \mathrm{atividade} \mathrm{6.} \mathrm{Analisando} \mathrm{a} \mathrm{médio} \mathrm{prazo} \mathrm{também}$ observamos melhora importante em um caso (IIB-10), que passou da escala de atividade 4 para 6 e, depois, para 7. Finalmente, a curto prazo, tivemos 5 casos, tendo havido: uma remissāo (IIA-4) em paciente que ao ser examinado inicialmente estava em escala de atividade 6 e três casos que obtiveram melhora (IIA-10, IIB-13, IIB-14). Houve um paciente (IIA-5) que, ao ser reavaliado 10 meses após, apresentou piora do quadro (de escala de atividade 7 para 6). Para os 13 pacientes submetidos a cirurgia, os resultados foram os seguintes, portanto: 10 melhoras (seis a longo prazo, um a médio prazo e três a curto prazo de observação), dois casos de remissão (IIB-15 longo prazo, IIA-4 curto prazo) e um caso de piera (IIA-5).

Os resultados, com tratamento clínico apenas, ficaram prejudicados por falta de seguimento (voltaram às cidades de origem e perdemos o contato). Acompanhamos dois casos: um do grupo I (I-1), que permaneceu estacionário atế quando se fechou o tempo de inclusão no trabalho; outro, do grupo $\mathrm{V}$ (V-6), que também se mantém estacionário mas com graves limitaçōes, advindas do acometimento da musculatura bulbar.

Cinco pacientes foram submetidos a plasmaferese no pré-operatório (IIB-1, IV-1, V-2, V-5, V-7) (Tabela 6) havendo melhora dramática em um caso (IV-1), melhora significativa em dois (V-2 e V-7), discreta em um (IIB-1), nenhuma em um caso (V-5). No pós-operatório a plasmaferese foi utjlizada em 4 pacientes (I-3, IIB-4, IIB-11, IV-1), com resposta excelente no caso I-3 (da escala de atividade 2 em que ficou no pós-operatório após complicações infecciosas, voltou à escala 7 quando submetido à plasmaferese); o caso IV-1, que flutuava muito no pós-operatório, fez duas séries de plasmaferese, passando da escala 4 para 7 e, depois, estabilizando em 6 . Dos 4 pacientes submetidos a plasmaferese no pós-operatório houve melhera em trẻs, portanto. Apenas o caso IIB-4, nåo melhorou. Pudemos observar que a plasmaferese usada em crise miastênica (IV-1) permitiu ao paciente sair dessa condiçāo gravíssima, dependente do respirador, ser submetido a cirurgia e obter melhora posterior. A associação da plasmaferese com cirurgia em 5 casos mostrou os seguintes resultados: a 


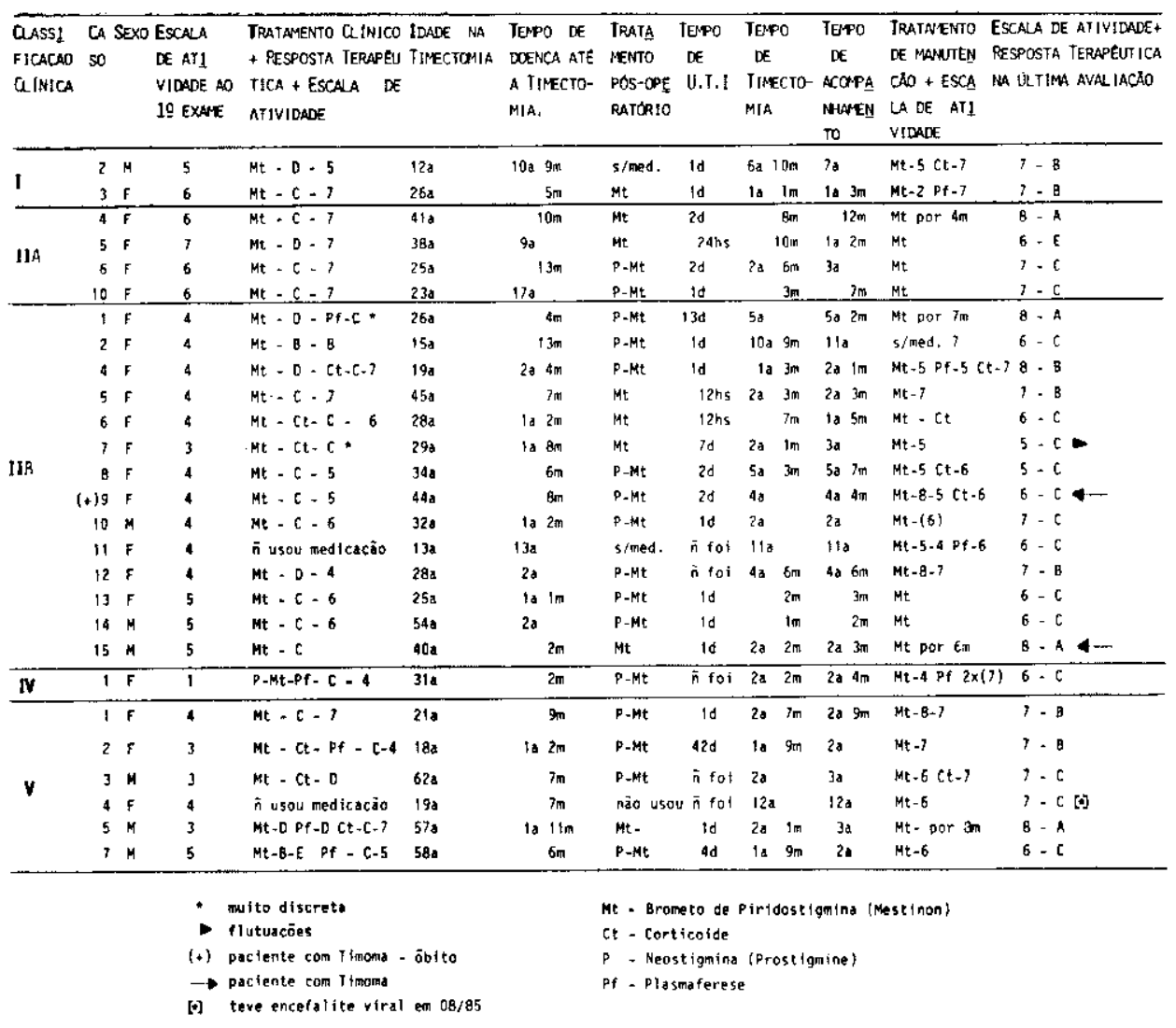

Tabela; - Evolução de 27 vacientes timectomizados.

longo prazo, uma remissão (IIB-1) e duas melhoras (IIB-11, IV-1) e mais duas melhoras, a médio prazo (I-3, V-7). Deve-se ressaltar que o caso IIB-1, que obteve remissão a longo prazo, năo se beneficiou da plasmaferese sugerindo-se, portanto, que tal evolução se deva à cirurgia. O paciente V-7 que teve piora no acompanhamento pré-operatório com a plasmaferese, voltou ao estágio inicial, foi operado e obteve melhora com dois anos de acompanhamento.

Seis pacientes foram submetidos a tratamento corticoterápico no pré-operatório (Tabela 7) e, destes, três obtiveram melhora substancial (IIB-4, IIB-6, V-5), pulando dois ou três dograus na escala de atividade; outros dois casos tiveram melhora muito discreta (II B-7, $\mathrm{V}-2)$ e um não respondeu a esta modalidade terapêutica (V-3). O caso V-2 obteve melhora com a plasmaferese, permitindo a realizaçāo da cirurgia em melhores condições. Este caso esteve antes internado em outro hospital onde, durante crises miastenicas, foi submetido a tratamento com corticosteróide e melhorou mas, por ocasiâo da retirada, piorou e foi internado em nosso hospital, onde fizemos plasmaferese seguida de cirurgia (ficou 42 dias na UTY). Desses 6 pacientes, três necessitaram de corticoterapia no pós-operatírio (IIB-4, IIB-6, V-3); acrescidos de outros três novos casos (I-2, IIB-8, IIB-9), obteve-se melhora en todos. Não foi possivel, no entanto, retirar esta medicação em qualquer deles. Ainda que essa tentativa fosse feita muito gradualmente, havia recidiva dos sintomas e necessidade de dose de manutençăo. Os pacientes IIB-7, V-2, V-5 nāo necessitaram voltar ao uso de corticosteróide sendo que, na avaliação pós-cirúrgica final: IIB-7 teve melhora (da escala 3 para 5); V-2 respondeu extraordinariamente após a cirurgia, chegando a remissão, mas voltando a necessitar de piridostigmina posteriormente; V-5 teve remissão a longo prazo, pós-cirurgia. $\mathrm{Na}$ avaliação final tivemos, portanto, 9 pacientes que usaram corticóide e se submeteram a cirurgia com um caso de remissão a longo prazo (V-5) e 4 de melhura (I-2, IIB-7, IIB-8, 


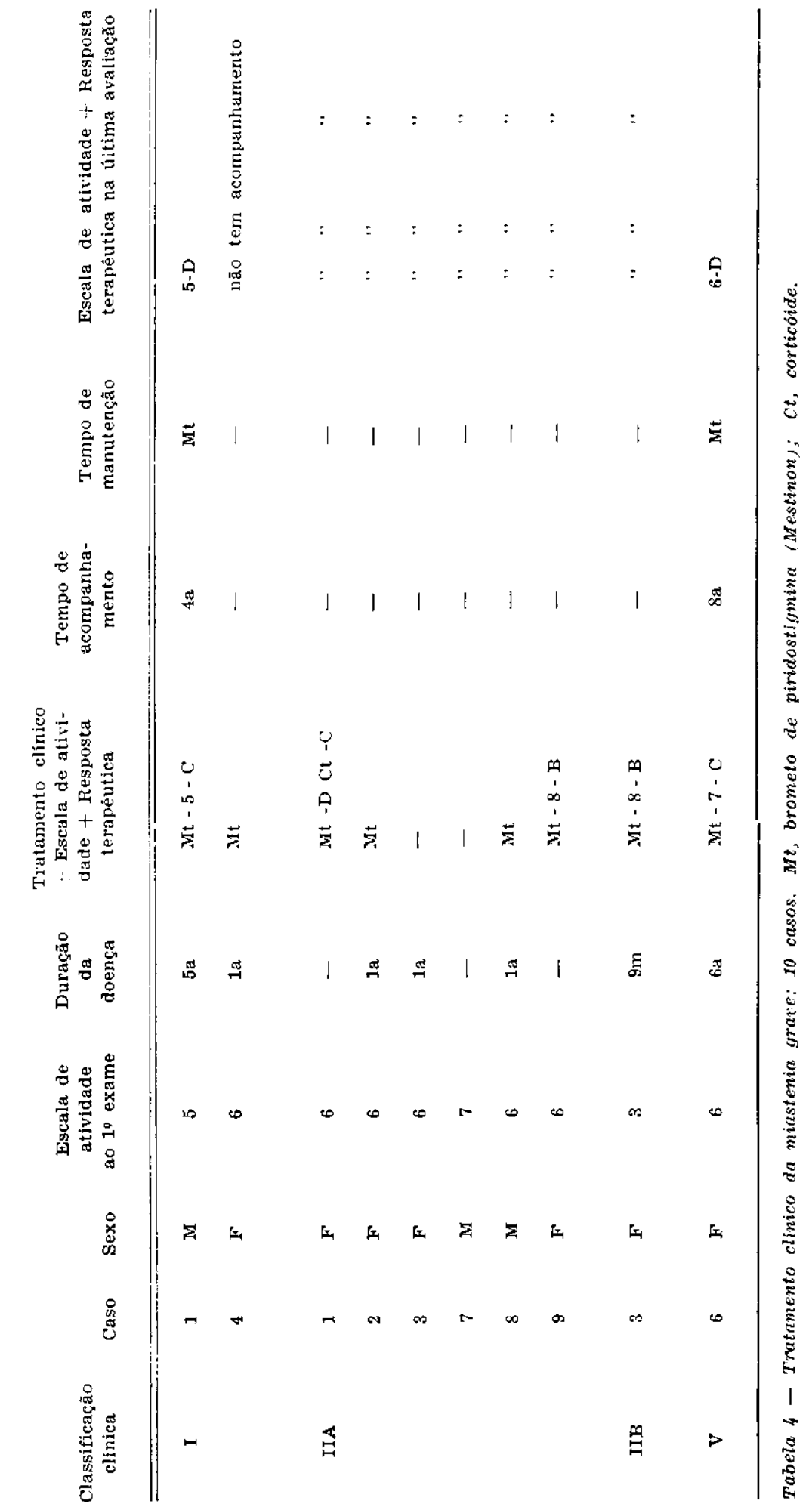




\begin{tabular}{|c|c|c|c|c|c|}
\hline $\begin{array}{l}\text { Classificação } \\
\text { clinica }\end{array}$ & Caso & $\begin{array}{c}\text { Tempo de } \\
\text { doença }\end{array}$ & $\begin{array}{l}\text { Escala de } \\
\text { atividade } \\
\text { no início }\end{array}$ & $\begin{array}{l}\text { Escala de } \\
\text { atividade após } \\
\text { timectomia }\end{array}$ & $\begin{array}{l}\text { Tempo de } \\
\text { tratamento }\end{array}$ \\
\hline \multirow[t]{4}{*}{ IIA } & 4 & $10 \mathrm{~m}$ & 6 & 8 & $8 \mathrm{~m}$ \\
\hline & 5 & $9 a$ & 7 & 6 & $10 \mathrm{~m}$ \\
\hline & 6 & $13 \mathrm{~m}$ & 6 & 7 & $2 a 6 m$ \\
\hline & 10 & $17 a$ & 6 & 7 & $3 \mathrm{~m}$ \\
\hline \multirow[t]{7}{*}{ IIB } & 2 & $13 \mathrm{~m}$ & 4 & 6 & $10 \mathrm{a} 9 \mathrm{ml}$ \\
\hline & $\mathbf{5}$ & $7 \mathrm{~m}$ & 4 & 7 & $2 \mathrm{a} 3 \mathrm{~m}$ \\
\hline & 10 & 1a. $2 \mathrm{~m}$ & 4 & $6 \mathrm{p} / 7$ & $2 a$ \\
\hline & 12 & $2 a$ & 4 & $8 p / 7$ & $4 \mathrm{a} 6 \mathrm{~m}$ \\
\hline & 13 & $13 \mathrm{~m}$ & 5 & 6 & $2 \mathrm{~m}$ \\
\hline & 14 & $2 a$ & 5 & 6 & $1 \mathrm{~m}$ \\
\hline & 15 & $2 \mathrm{~m}$ & 5 & 8 & $2 \mathrm{a} 2 \mathrm{~m}$ \\
\hline \multirow[t]{2}{*}{$\mathrm{V}$} & 1 & $9 \mathrm{~m}$ & 4 & 8 p/ 7 & $2 \mathrm{a} 7 \mathrm{~m}$ \\
\hline & 4 & $7 \mathrm{~m}$ & 4 & $6 \mathrm{p} / 7$ & $12 a$ \\
\hline
\end{tabular}

Tabela J̈- Pacientes com miastenia grave submetidos só a timectomia: 13 casos.

\begin{tabular}{|c|c|c|c|c|c|c|c|}
\hline $\begin{array}{l}\text { Classifi- } \\
\text { caçāo } \\
\text { clinica }\end{array}$ & Caso & $\begin{array}{l}\text { Tempo } \\
\text { de } \\
\text { doenga }\end{array}$ & $\begin{array}{l}\text { Escala de } \\
\text { atividade } \\
\text { no inicio }\end{array}$ & $\begin{array}{c}\text { Escala de } \\
\text { atividade com } \\
\text { plasmaferese } \\
\text { pré }\end{array}$ & $\begin{array}{l}\text { Escala de } \\
\text { atividade } \\
\text { com } \\
\text { timectomia }\end{array}$ & $\begin{array}{c}\text { Escala de } \\
\text { atividade com } \\
\text { plasmaferese } \\
\text { pós }\end{array}$ & $\begin{array}{l}\text { Tempo de } \\
\text { tratamento }\end{array}$ \\
\hline I & 3 & $5 \mathrm{~m}$ & 6 & - & 2 & 7 & 1a $1 \mathrm{n}$ \\
\hline \multirow[t]{3}{*}{ IIB } & 1 & $4 \mathrm{~m}$ & 4 & 4 & 8 & - & $\mathbf{5 a}$ \\
\hline & 4 & $2 \mathrm{a} 4 \mathrm{~m}$ & 4 & - & 5 & 5 & $1 \mathrm{a} 3 \mathrm{~m} *$ \\
\hline & 11 & $13 a$ & 4 & - & $5 \mathrm{p} / 4$ & 6 & $11 \mathrm{a}$ \\
\hline IV & 1 & $2 \mathrm{~m}$ & 1 & 4 & 4 & $7 \mathrm{p} / 6^{*}:$ & $2 \mathrm{a} 2 \mathrm{~m}$ \\
\hline \multirow[t]{3}{*}{$\mathrm{V}$} & 2 & 1a $2 \mathrm{~m}$ & 3 & 4 & 7 & - & $1 \mathrm{a} 9 \mathrm{~m}^{*}$ \\
\hline & 5 & $1 \mathrm{a} 11 \mathrm{~m}$ & 3 & 3 & 8 & $\rightarrow$ & $2 \mathrm{a} 1 \mathrm{~m} *$ \\
\hline & 7 & $6 m$ & $5 * * *$ & 5 & 6 & - & 1a $9 \mathrm{~m}$ \\
\hline
\end{tabular}

Tabela 6 - Pacientes submetidos a timectomia +plasmaferese: 8 casos. *, usraram corticóide; **, realizou plasmaferese duas vezes; ***, piorou com a evolucâo.

\begin{tabular}{|c|c|c|c|c|c|c|c|}
\hline $\begin{array}{l}\text { Classifi- } \\
\text { caçāo } \\
\text { clinica }\end{array}$ & Caso & $\begin{array}{l}\text { Tempo } \\
\text { de } \\
\text { doença. }\end{array}$ & $\begin{array}{l}\text { Escala de } \\
\text { atividade } \\
\text { no inicio }\end{array}$ & $\begin{array}{c}\text { Escala de } \\
\text { atividade com } \\
\text { corticóide } \\
\text { pré }\end{array}$ & $\begin{array}{l}\text { Escala de } \\
\text { atividade } \\
\text { após } \\
\text { timectomia }\end{array}$ & $\begin{array}{l}\text { Tempo de } \\
\text { tratamento }\end{array}$ & $\begin{array}{l}\text { Escala de } \\
\text { atividade com } \\
\text { corticóide } \\
\text { pós }\end{array}$ \\
\hline I & 2 & $10 \mathrm{a} 9 \mathrm{~m}$ & 5 & - & 5 & $6 \mathrm{a} 10 \mathrm{~m}$ & 7 \\
\hline \multirow[t]{5}{*}{ IIB } & 4 & $2 a \mathrm{am}$ & 4 & 7 & 5 & $1 \mathrm{a} 3 \mathrm{~m}$ & $7 \mathrm{p} / 8$ \\
\hline & 6 & 1a $2 \mathrm{~m}$ & 4 & 6 & 6 & $7 \mathrm{~m}$ & 6 \\
\hline & 7 & 1a $8 \mathrm{~m}$ & 3 & 3 & 5 & $2 \mathrm{a} 1 \mathrm{~m}$ & 一 \\
\hline & 8 & $6 m$ & 4 & - & 5 & $5 a 3 m$ & $6 \mathrm{p} / 5$ \\
\hline & 9 & $8 \mathrm{~m}$ & 4 & - & $8 \mathrm{p} / 5$ & $4 a$ & 6 \\
\hline \multirow[t]{3}{*}{$\mathrm{v}$} & 2 & Ia $2 \mathrm{nt}$ & 3 & 3 & 7 & $1 \mathrm{a} 9 \mathrm{~m}$ & - \\
\hline & 3 & $7 \mathrm{nu}$ & 3 & 3 & 6 & $2 a$ & 7 \\
\hline & 5 & 1a $11 \mathrm{~m}$ & 3 & 7 & 8 & $2 \mathrm{a} 1 \mathrm{~m}$ & - \\
\hline
\end{tabular}


11B-9). A médjo prazo, um paciente chegou a ter remissão mas voltou a precisar do anticolinesterásico ficando classificado como melhora (IIB-4), dois outros com melhora (V-2, V-3) e, a curto prazo, uma melhora (IIB-6). Este último caso voltou à sua cidade de origem onde apresentou flutuaçōes importantes, chegando a parada respiratória e necessidade de traqueostomia por três meses; tivemos notícias dele recentemente (anós fechado o prazo de inclusão no trabalho), ainda se encontrando com corticóide (acima de dois anos de pós-operatório). Quanto aos efeitos colaterais do medicamento foram encontrados Cushing, acne, amenorréia, úlcera péptica, gastrite, catarata, porose óssea em falanges, diabetes, artralgias em grandes articulaçôes, fragilidade capilar, telangiectasias, edema de membros inferiores (Tabela 8 ).

E necessário saljentar que un jaciente submeteu-se a timectomia e irradiarāo por timoma não invasivo (I1B-15) e está com remissão da doeņ̣a, com dois anos e dois méses de acompanhamentu. O outro caso de timoma submetido a irradiação melhorou e chegou à remissão no prazo de três anos, voltou a piorar, teve que usar corticosteróides em doses altas com relativa melhora e, soubemos, faleceu de infarto de miocárdio, complicação esta talvez devida ao uso prolongado do corticosteroide (4 anos após timectomia). Tivemos conhecimento de um óbito ocorrido durante o ato cirúrgico por massa mediastinal com miastenia grave, porém este caso não está incluido neste estudo por insuficiéncia de dadòs.

O estudo anátomo-patológico do timo revelou nítida predominância de hiperplasia (19 casos), seguida do achado de atrofia em três casos, hipertrofia em dois e timoma em dois casos.

$\begin{gathered}\text { Classifi- } \\ \text { caçấ } \\ \text { clínica }\end{gathered}$
I

Tabela $8-$ Efeitos coluteruis dos corticosteróides.

\section{COMENTARIOS}

Em relaçào às doenças associadas à miastenia grave, conforme se mostra na tabela 2, nossos dados repetem os da literatura 1,14,36, ressaltando-se a presença de grande número de endocrinopatias. Algumas associaçōes foram consideradas fortuitas como enxaqueca e convulsōes, pela sua alta incidência na população em geral, e hemorragia subaracnóidea, por ter ocorrido uma única vez. Devemos, no entanto, chamar a atenção para a presença de imunopatias associadas em nossa casuística de MG, como tireoidite de Hashimoto, púrpura trombocitopênica e dados laboratoriais de alteraçāo de globulinas e imunoglobulinas.

Pudemos observar, na análise de nossos resultados (Tabela 9 ), que pacientes do grupo IIA, IIB e V obtiveram beneficios com o tratamento cirúrgico. A análise a longo prazo mostrou que 7 dos pacientes submetidos somente a timectomia tiveram melhora importante (remissão ou subida de mais de um grau na escala de atividade) e, a este dado, poderia ainda se acrescentar o de um paciente que melhorou apenas um ponto na escala. A este grupo temos ainda que adicionar aqueles que tiveram melhora a médio e curto prazos e que ainda nāo tiveram acompanhamento suficiente para serem incluidos entre os observados a longo prazo. Podemos, agora, comparar nossos resultados com os de Scadding e col.26, que encontraram taxa de remissão e melhora 


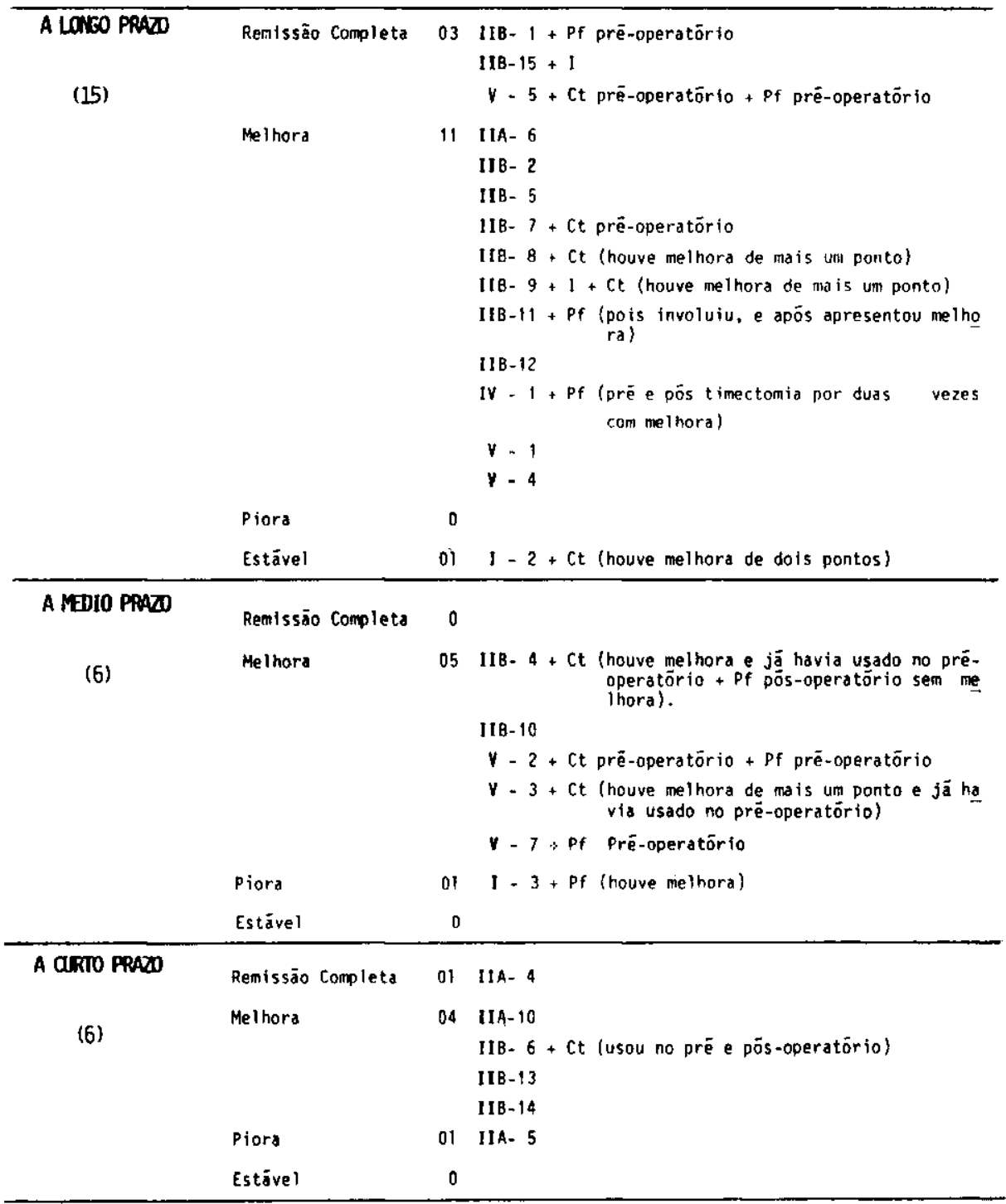

Tabela 9 - Análise das respostas à timectomia em relação ao primeiro exame. Ct, corticóide; Pf, plasmaferese; $I$, irradiacäo.

de $68,2 \%$ (total de 280 pacientes, sendo 243 tinlectomizados) e cuja taxa de remissāo espontânea (tratados apenas com anticolinesterásicos) foi de $11,4 \%$ e de melhora, de $16 \%$ (total de $27,4 \%$ de 37 pacientes). Em relaçāo ao grupo timectomizado tiveram eles indice de piora de $26,7 \%$ e nenhum efeito em $5 \%$, sendo que no grupo não operado houve, respectivamente, piora em $43,2 \%$ e $29,5 \%$ permaneceram inalterados. Nos pacientes aos quais foi oferecida a possibilidade de tratamento cirúrgico mas que, por opção, a rejeitaram, tivemos a oportunidade de seguimento a longo prazo apenas de dois: um com miastenia predominantemente ocular e que começa agora a se queixar de traqueza proximal em membros superiores e outro, classificado no grupo $V$, que está estabilizado, porém com todas as limitaçōes próprias desta forma grave de doença. Nossos dados e aqueles citados, corroboram os de outros 1 , que mostraram baixa taxa de remissia espontânea $(7,1 \%)$ e, em que pese o fato de no grupo de timectomizados 
terem sido incluidos formas mais graves da doença, conforme os autores salientam, houve taxa de remissão de $31,5 \%$. Ressalta-se ainda, no grupo nāo operado, taxa de piora elevada a quem então foi oferecido o tratamento com corticosteróides. Finalmente, gostariamos de salientar os dados de Buckingham e col.3 que, em estudo retrospectivo porém pareado para sexo, idade, gravidade de doença (de 563 pacientes, 104 foram timectomizados $\mathrm{e}$, destes, apenas $\mathbf{8 0}$ foram incluidos para atender às exigências de parear com 80 não operados) encontraram: remissăo completa em 27 pacientes cirúrgicos e em 6 casos clínicos; melhora em 26 cirúrgicos em comparação com 13 medicamentosos. Ainda a sobrevivência a longo prazo era maior entre os pacientes operados (11 óbitos em comparaçāo com 34).

Ao analisar o tratamento com corticosteróides isoladamente, valemo-nos do estudo de Pascuzzi e col.23 que, tratando 116 pacientes, observaranı remissão en $27(6 \%)$, bons resultados em $52,6 \%$ e maus em $19,8 \%$, sendo que tiveram de indicar a timectomia posteriormente em 51 pacientes dos 93 considerados como tendo resposta satisfatória à prednisona. Interessante assinalar que destes, 11 tinham timoma, dos quais 10 obtiveram melhora. Outro estudo relativo à eficácia do corticosteróide é o de Sghirlanzoni e col.28, que também obtiveram indice de methora de $92 \%$ com o tratamento crônico de corticosteróide. Em ambos, porém, os autores são unânimes em afirmar que os efeitos colaterais do medicamento estão longe de serem despreziveis. Nossos resultados mostram que tanto a timectomia como os corticosteróides têm lugar no manejo terapêutico da $M G$, restando portanto caracterizar esse lugar. Pêla análise de nossos resultados e dos dados da literatura $5,6,14,23,27,28$ sugerimos não usar o corticosteróide de rotina no pré-operatório devido não só aos efeitos colaterais, conforme ocorreu principalmente com os casos V-5, IIB-4, IIB-8, mas principalmente pela dificuldade de retirada posterior, sendo, no entanto, recomendado em casos de restrição importante da função respiratória que não melhora com a plasmaferese e anticolinesterásicos, como nosso paciente V-5. Esta observação também ć válida para o pós-operatório, sendo no entanto o emprego desta droga aceito naqueles casos em que o paciente não consegue manter uma vida social e/ou economicamente ativa, nesmo que seja a miastenia considerada ocular pura (caso $[-2$, cuja ptose severa prejudicava seus estudos).

Tivemos poucos casos analisados que foram submetidos à plasmaferese. No entanto, desde que Pinching e col.24 publicaram os primeiros resultados do tratamento de pacientes miastênicos com a plasmaferese, muitos outros grupos adotaram a técnica 4,12,20 e mostraram o efeito transitório da plasmaferese sobre as proteinas séricas e anticorpos anti-receptor de acetilcolina. Ainda que o nivel de anticorpos circulantes anti-receptor de acetilcolina não seja estreitamente correlacionado à gravidade da doença 35 , observa-se que ocorrem remissōes temporárias da miastenia após plasmaferese e sua indicaçāo primeira é, pois, a de tirar o paciente de crises miastênicas. Afirma Matell 15 que, após o uso dessa técnica, não houve necessidade de se lançar mão de traqueostomia nos últimos três anos em sua clínica de Estocolmo. Como este autor, indicamos a plasmaferese para crises miastênicas e, também, a consideramos como primeira escolha no pré-operatório de pacientes com diminuiçāo importante da capacidade vital $(50 \%)$, o que também preconizam Spence e col.32. Caso não observemos resposta a esta medida terapêutica, entāo recorremos ao corticosteróide. Indicamos a plasmaterese também nos casos de piora no pós-operatório, enquanto se aguarda o tempo preconizado (dois anos) para melhora com a timectomia, o que se observou em três de quatro pacientes de nossa casuística, tendo sido já relatados casos de remissão prolongada após essa modalidade terapêutica 35.

Em nosso estudo, nāo tivemos qualquer caso em que se empregou imunossupressor não-esteróide, porém é mostrado na literatura que estes medicamentos têtn suas indicações especificas e, tambèm, muitas limitações. Afirmam os autores 21 que os imunossupressores azatioprina e ciclofosfamida levam a uma taxa de melhora na miastenia entre 80 e $90 \%$ e que têm sua indicação principal nos casos associados a timoma. Outros 15 advogam o uso de azatioprina em casos corticóide-dependentes, porém ressaltam como desvantagem, além do tempo mais prolongado para começar a agir quando comparado aos corticóides, a dificuldade de retirada do medicamento. Há ainda a assinalar efeitos colaterais graves que podem ocorrer sobre o sistema hematopoiético, a incidência de infecções oportunistas graves e de neoplasias. Novos tipos de imunossupressores têm sido propostos como a ciclosporina 34 mas, como Drachman 7 enfatiza, a substância năo foi testada comparativamente a outras formas de tratamento e, além disso, tem efeitos colaterais serissimos (renais, por exemplo) que tornam seu uso năo recomendado em primeira instância. 
A utilização de timectomia como primeira escolha é advogada nas formas de miastenia predominantemente ocular, pela possibilidade de generalizaçăo posterior, para evitar o uso prolongado de anticolinesterásicos, cuja potencialidade de agravamento da lesão de placa mioneural foi demonstrada em animais 18 e sugerida em humanos 25 e, finalmente, pela possibilidade da existência de timomas sem expressão radiológica, porém constatados histologicamente 27 . Pela análise da relação risco $\times$ benefício concluímos pela indicação da timectomia como primeira escolha, secundada pelos corticosteróides e, posteriormente; outros imunossupressores. A plasmaferese, de validade temporária está indicada apenas como medida de urgência.

Ficamos, pois, aguardando melhor conhecimento da etiopatogenia da doença para que, com sua utilização, se disponha de tratamento de base científica adequada, como nos pãece a proposiçăo do uso de anticorpos anti-idiotípicos, já indicado em base experimental em animais 31 .

Agradecimentos - Os autores desejam expressar seus agradecimentos a toda a equipe de Neurologia do HBDF e de Neurofisiologia do HDAL/SARAH e HBDF, que permitiu a realização deste estudo, aos responsáveis pela Cirurgia sob a orientação do Dr. Manoel Ximenes Neto e de Plasmaferese (Dr. Cid L. Vale e Dra. Jussara S. Oliveira).

\section{REFERENCIAS}

1. Assis JL, Marchiori PE, Scaff M, Zambon AA — Tratamento conservador e timectomia na nijastenia grave. Arq Neuro-Psiquiat (São Paulo) 45:119, 1987.

2. Bever CT, Aquino AV, Penn AS, Lovelace RE, Rowland LP - Prognosis of ocular myasthenia, Ann Neurol 14:516, 1983.

3. Buckingham JN, Howard FM Jr, Bernatz PE, Spencer Payne W, Harrison EG Jr, O'Brien PC, Weilana LH - The value of thynectomy in myasthenia gravis: á computer assisted matched study. Ann Surg 184:453, 1976.

4. Dau PC, Lindstrom JM, Cassel CK, Denys EH, Shev EE, Spitler LE - Plasmapheresis and immunossuppressive drug therapy in myasthenia gravis. New Engl J Med 297: $1135,1977$.

5. Drachman DB - Myasthenia gravis. New Engl J Med 298:136, 1978.

6. Drachman DB - Myasthenia gravis. New Eng! J Med 298:186, 1978.

7. Drachmau DB - Present and future treatment of myasthenia gravis. New Engl J Med $316: 743,1987$.

8. Engel AG, Lambert EH, Howard FM - Immune complexes (IgG and $\mathrm{C}_{3}$ ) at the motor end-plate in myasthenia gravis: ultra-strutural and light microscopic localization and electrophysiologic correlations. Mayo Clin Proc 52:267, 1977.

9. Engel AG - Myasthenia gravis and myasthenic syndromes. Ann NJeurol 16:519, 1984.

10. Hankins JR, Mayer RF, Satterfield JR, Turney SZ, Attar S, Seçueira AJ, Thompson BW, McLaughlin JS - Thymectomy for myasthenia gravis: 14 -year experience. Ann Surg $201: 618,1985$.

11. Haynes BF, Harden EA, Olanow CW, Eisenbarth GS, Wechsler AS, Hensley LL, Roses $\mathrm{AD}$ - Effect of thymectomy on puripheral lymphocyte subsets in myasthenia gravis: selective effect on $T$ cells in patients with thymic atrophy. $\mathrm{J}$ Immunol 131:773, 1983.

12. Jacobsen H, Thorlacius S, Aaarli JA - Plasmapheresis in myasthenia gravis: clinical results and changes in serum proteins. Acta Neurol Scand 65(Suppl 90):128, 1982.

13. Kurtzke JF - Epidemiology of myasthenia gravis. Advances in Neurology, vul 19 . Raven Press, New York, 1978.

14. Lisak RP, Barchi RL - Myasthenia gravis. Major Problems in Neurology, vol 11, 1982.

15. Matell G - Myasthenia gravis: an autoimmune receptor disease. Acta Neurol Scand 65 (Suppl 90):112, 1982. 
16. McQuillen MP, Leone MG - A treatment carol: thymectomy revisited. Neurology 27:1103, 1977.

17. Moore HJ, Woods EL - Myasthenia gravis: associated antibodies in asymptomatic thymoma. I Thorac Cardiovasc Surg 89:308, 1985.

18. Munsat TL - Anticholinesterase abuse in myasthenia gravis. J Neurol Sci 64:5, 1984.

19. Namba T, Brunner NG, Grob D - Myasthenia gravis in patients with thymoma, with particular reference to onset after thymectomy. Medicine $57: 411,1978$.

20. Newsom Davis $J$, Vicent A, Ward CD, Wilson SG, Pinching AJ - Plasmapheresis exchange: short and long-term benefits. In Dau PC (ed): Plasmapheresis and the Immunubiolgy of Myasthenia Gravis, Houghton Mifflin, Boston, 1979, pg 199.

21. Niakam E, Harati $\mathrm{Y}$, Roiak LA - Immunossuppressive drug therapy in myasthenia gravis. Arch Neurol 43:155, 1986.

22. Osserman KE - Myasthenia Gravis. Grune \& Stratton, New York, 1958, pg $78,86$.

23. Pascuzzi RM, Branch Coslett $H$, Johns TR - Long-term corticosteroid treatment of myasthenia gravis: report of 116 patient:3. Ann Neurol 15:291, 1984.

24. Pinching AJ, Peters DK, Newson-Davis $J$ - Remission of myasthenià gravis following plasma exchange. Lancet $2: 1373,1976$.

25. Rowland LP, Korengold MC, Jaffe IA, Berg L, Shy GM - Prostigmine induced muscle weakness in myasthenia gravis patients. Neurology 5:89, 1955.

26. Scadding GK, Havard CWH, Lange MJ, Domb I - The long term experience of thymectomy for myasthenia gravis. J Neurol Neurosurg Psychiat 48:401, 1985.

27. Schumm F, Wiethölter H, Moghadam AF, Dichgan J - Thymectomy in myasthenia with pure ocular symptoms. J Neurol Neurosurg Psychiat 48:332, 1985.

28. Sghirlanzoni A, Peluchetti D, Mantegazza R, Fiacchino $\mathbf{F}$, Cornelio $F$ - Myasthenia gravis: prolonged treatment with steroids. Neurology $34: 170,1984$.

29. Simpson JA - An evaluation of thymectomy in myasthenia gravis. Brain 81:112, 1958.

30. Simpson JA - Myasthenia gravis: a new hypothesis. Scot Med J 5:419, 1960.

31. Souroujon MC, Pachner AR, Fuchs $\mathbf{S}$ - The treatment of passively transferred experimental myasthenia with anti-idiotypic antibodies. Neurology 36:622, 1986.

32. Spence PA, Morin JE, Katz M - Role of plasmapheresis in preparing nyasthenic patient: for thymectomy: inicial results. Canad J Surg 27:303, 1984.

33. Tejedor ED, Orozco JP — Miastenia grave y sindromes miasténicas. In Conyreso Nacional de Neurologia (jun, 1984). Anais, San Sebastián, 1984.

34. Tindall RSA, Rollins JA, Phillips JT, Greenlee RG, Wells L, Belendiuk G - Preliminary results of a double-biind randomized, placebo-controlled trial of cyclosporine in myasthenia gravis. N Engl J Med $316: 719,1987$.

35. Thorlacius S, Aaarli JA, Jacobsen $\mathbf{H}$, Halvorsen $\mathrm{K}-$ Plasna excnange in myasthenia gravis: clinical effect. Acta Neurol Scand $72: 464,1985$.

36. Werneck LC, Teive HAG - Miastenia grave: avaliação clínica e terapêutica de 55 casos. Arq Neuro-Psiquiat (São Paulo) 45:379, 1987. 